Article

\title{
An Optimal Phase Arrangement of Distribution Transformers under Risk Assessment
}

\author{
Chia-Sheng Tu ${ }^{1}$, Chung-Yuen Yang ${ }^{2} \mathbb{D}$ and Ming-Tang Tsai ${ }^{2, *}$ \\ 1 College of Intelligence Robot, Fuzhou Polytechnic, Fuzhou 350108, China; lkjhh5302@yahoo.com.tw \\ 2 Department of Electrical Engineering, Cheng-Shiu University, Kaohsiung 833, Taiwan; \\ k6548@gcloud.csu.edu.tw \\ * Correspondence: k0217@gcloud.csu.edu.tw; Tel.: +886-7-7310606
}

Received: 15 October 2020; Accepted: 4 November 2020; Published: 9 November 2020

\begin{abstract}
This paper presents a phase arrangement procedure for distribution transformers to improve system unbalance and voltage profile of distribution systems, while considering the location and uncertainties of the wind turbine (WT) and photovoltaics (PV). Based on historical data, the Monte Carlo method is used to calculate the power generation value-at-risk (VAR) of WTs/PVs installed under a given level of confidence. The main target of this paper is to reduce the line loss and unbalance factor during 24-hour intervals. Assessing the various confidence levels of risk, a feasible particle swarm optimization (FPSO) is proposed to solve the optimal location of WTs/PVs installed and transformer load arrangement. A three-phase power flow with equivalent current injection (ECI) is analyzed to demonstrate the operating efficiency of the FPSO in a Taipower feeder. Simulation results will support the planner in the proper location of WTs/PVs installed to reduce system losses and maintain the voltage profile. They can also provide more risk information for handing uncertainties when the renewable energy is connected to the distribution system.
\end{abstract}

Keywords: distribution transformer; value-at-risk; particle swarm optimization; Monte Carlo method

\section{Introduction}

A distribution system comprises many components which supply energy to the loads. In Taiwan, the Taipower Company (TPC) usually used open-wye/open-delta transformers to supply either three-phase load or single-phase load for economical operation [1]. Problems with the planning of open-wye/open-delta transformers result in phase unbalance which causes more line loss, the drop of communication quality, and the reduction of equipment life [2,3]. A graver consequence of the phase unbalance is that the grounding relay jumps off. However, the planner desires to operate the distribution system in a more balanced status to promote the power quality and improve operation efficiency.

Distribution generators (DGs), such as wind turbines (WTs) or photovoltaics (PVs), which are located near the energy customers, play an important role in the energy sector [4,5]. The use of DGs in a distribution system has several advantages, depending on the allocation of DGs. The stochastic generation of some DGs generates power output which often does not match the load demand profile. However, the greatest challenge with DGs lies in the intermittent/unpredictable nature of the renewable DGs, as they are dependent on weather and climatic conditions. While a huge penetration of DGs in the distribution system may have a significant impact on voltage profiles of systems, it may lead to a risk due to the generation of DGs in a distribution system. Moreover, the safety operation of the distribution system needs to handle the risk of changes in system supply and demand, when the uncertain power of WTs/PVs is injected into the distribution system. Financial institutions use value-at-risk (VAR) to evaluate risk in uncertainty, by measuring the minimum loss expected in 
a given portfolio within an assigned period [6,7]. It is important to carry out risk assessment and seek the optimal operation in the case of uncertain power supply.

Since the open-wye/open-delta transformer simultaneously served the single-phase/three-phase loads, loads reassigning through prime phase resequencing will balance the current of three phases, thereby leading to minimal loss in the distribution feeder. The problem becomes more complex when the uncertain power of WTs/PVs is added into the system. There have been many discussions about transformer rearrangement in the past. Genetic algorithm (GA) is used to solve the phase arrangement of distribution transformers; this improves the system unbalance and loss reduction [8,9]. Non-Dominated Sorting Genetic Algorithm II (NSGA-II) is used in the connection of distribution transformers for phase balance of primary circuits to reach both loss reduction and unbalance improvement $[10,11]$. An automatic phase load balancing method is applied for phase-balancing of the distribution feeder to reach better operating performance in a distribution feeder [12]. Reference [13] used the automatic transformer load balance to reduce the system loss on the primary distribution circuit. For the problem of the optimal connections between distribution transformer and primary feeder, six objectives were simultaneously solved by using the normalized weighting method [14]. Linear programming and dynamic programming is used to get the optimal phase arrangement of a distribution circuit. A three-phase power flow program with equivalent current injection method is used to simulate the system loss and unbalance factor in cases of transformer rearrangement, optimal load diversity, and mixed-type $[15,16]$. The problem with the phase arrangement of a distribution transformer involves high complexity in the search space, which includes the enormous number of feasible combinations in the phase rearrangement. Particularly, a grid-connected proportion of WTs/PVs power supply has a huge impact on the safe operation of the distribution system. Thus, this problem has become more complicated and challenging.

In the three-phase system, WTs/PVs are generally presented in the distribution system and directly linked to the single-phase distribution network. Inappropriate location and phase of WTs/PVs may lead to greater system losses and system unbalance [17,18]. WTs/PVs inherently operate in a highly variable way. Furthermore, it is a major challenge for the system operators due to the WTs/PVs merged into a distribution circuit. Moreover, the power generation of WTs/PVs is heavily affected by weather parameters, and highly disrupted with the changing weather. It is, therefore, difficult to accurately forecast the power generation of WTs/PVs; thus, there is inherent risk in system operation.

In this paper, the Monte Carlo method $[19,20]$ is used to calculate the generation value-at-risk (VAR) of presented WTs/PVs. Using the historical data of wind speed and global radiation, the generation VAR of WTs/PVs is derived under a given level of confidence. Considering the various confidence levels of risk, a feasible particle swarm optimization (FPSO) is proposed to optimally incorporate $\mathrm{WTs} / \mathrm{PV}$ into a distribution system and achieve optimal phase arrangement of distribution transformers under operating constraints. A three-phase power flow program with equivalent current injection (ECI) [21] is used to simulate and compare the system unbalance factor, voltage profiles, and system loss after the phase arrangement of transformers. A Taipower distribution system is proposed to demonstrate the operating efficiency and feasibility of the proposed algorithm. Results can help operators to not only appropriately install the WTs/PVs location but also the optimal phase arrangement of distribution transformers in order to reduce system loss and maintain the voltage profile. They can also provide more risk information in uncertain environments when the WTs/PVs are connected to the distribution system.

\section{Problem Description}

Figure 1 shows the load connection of open-wye/open-delta transformer. On the second side, the single-phase and three-phase loads are served by using the open-wye/open-delta transformer. At this time, it is equally served by two single-phase loads $\left(S_{A}\right.$ and $\left.S_{B}\right)$ at the primary side. The loads of $S_{A}$ and $S_{B}$ can be calculated as Equations (1)-(3). Therefore, it does not matter which type of 
transformer is needed to connect to the feeder. There are many options to connect to the A, B, and C phases of the primary side.

$$
\begin{gathered}
S_{A}=S_{A N}+S_{B N}+S_{A B}+S_{A C}<60^{0}+\frac{S_{3 \varnothing}}{\sqrt{3}}<30^{0} \\
S_{B}=S_{B C}+S_{A C}<-60^{0}+\frac{S_{3 \varnothing}}{\sqrt{3}}<-30^{0} \\
S_{C}=0
\end{gathered}
$$

$S_{A}, S_{B}$ and $S_{C}$ are the equivalent loads for each phase. $S_{A N}$ and $S_{B N}$ are the single-phase loads connected to the neural wires. $S_{A B}, S_{A C}$ and $S_{B C}$ are the single-phase loads connected to the two wires. $S_{3 \varnothing}$ is the three-phase load.

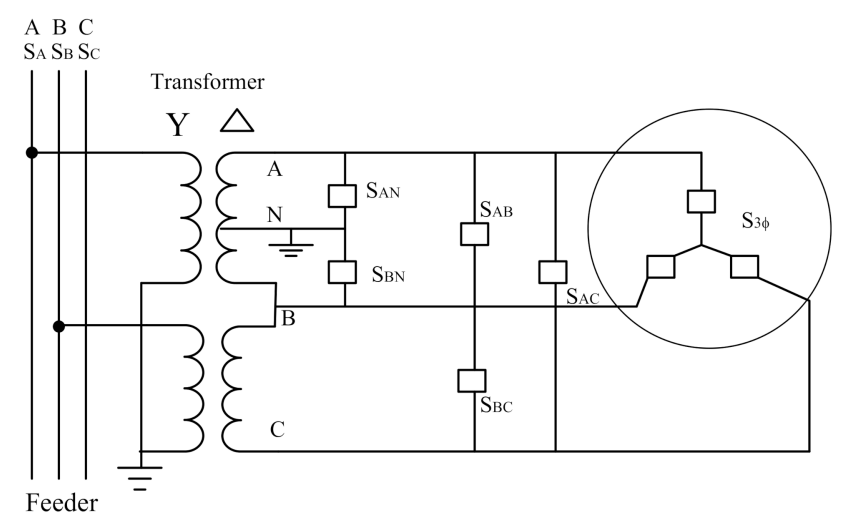

Figure 1. The loads of the open-wye/open-delta transformer.

Table 1 shows the feasible connection types for each distribution transformer, which has six connection types, three connection types, and three connection types for the three-phase transformer, open-wye/open-delta transformer, and single-phase transformer, respectively. The target of this paper is to solve the optimal connection types for distribution transformers for line loss reduction and system unbalance improvement.

Table 1. The feasible connection schemes for transformers.

\begin{tabular}{cccccccccc}
\hline Type & \multicolumn{3}{c}{$\begin{array}{c}3 \emptyset \\
\text { Transformer }\end{array}$} & \multicolumn{3}{c}{$\begin{array}{c}\text { Open-Wye/Open-Delta } \\
\text { Transformer }\end{array}$} & \multicolumn{3}{c}{$\begin{array}{c}\text { Single-Phase } \\
\text { Transformer }\end{array}$} \\
\hline 1 & A & B & C & A & B & x & A & x & x \\
\hline 2 & A & C & B & A & x & C & x & B & x \\
\hline 3 & B & A & C & x & B & C & x & x & C \\
\hline 4 & B & C & A & - & - & - & - & - & - \\
\hline 5 & C & A & B & - & - & - & - & - & - \\
\hline 6 & C & B & A & - & - & - & - & - & - \\
\hline
\end{tabular}

The objective function for phase rearrangement of transformers is to minimize the line loss during the 24-hour intervals. The problem is formulated as:

$$
\begin{gathered}
\operatorname{Min.} \operatorname{Obj}(\bullet)=\sum_{t=1}^{24} P_{\text {loss }, 3 \phi}^{t} \\
P_{\text {loss }, 3 \phi}^{t}=P_{\text {loss }, a}^{t}+P_{\text {loss }, b}^{t}+P_{\text {loss }, c}^{t}
\end{gathered}
$$


$P_{\text {loss }, 3 \phi}^{t}$ is the total line loss of distribution feeders at $t$-th time. $P_{\text {loss }, a}^{t} / P_{\text {loss }, b}^{t} / P_{\text {loss }, c}^{t}$ is the line losses of $\mathrm{a} / \mathrm{b} / \mathrm{c}$ phase at $t$-th time. The line loss of each phase can be defined as follows:

$$
P_{\text {loss }}^{t}=\frac{1}{2} \sum_{i=1}^{N B} \sum_{j=1}^{N B} \operatorname{Re}\left[Y_{i j}\right]\left[\left|V_{i}\right|^{2}+\left|V_{j}\right|^{2}-2\left|V_{i}\right|\left|V_{j}\right| \cos \theta_{i j}\right]
$$

where $N B$ is the total number of branches and $V_{i}$ is the voltage of $i$-th bus. $Y_{i j}$ is the admittance of branch $i-j$ and $\theta_{i j}=\theta_{i}-\theta_{j}$ is the phase angle difference between bus-i and bus-j.

The operating constraints are considered as follows.

\subsection{Power Balance}

The sum of power supply, and the VAR of PV output, and the VAR of WT output must be equal to the sume of load demand and line loss.

$$
\begin{aligned}
& P_{s w, a}^{t}+\sum_{s=1}^{S} P_{s_{-} e s t, a}^{t}+\sum_{w=1}^{W} P_{w_{-} e s t, a}^{t}=P_{\text {Load }, a}^{t}+P_{\text {loss }, a}^{t} \\
& P_{s w, b}^{t}+\sum_{s=1}^{S} P_{s_{-} e s t, b}^{t}+\sum_{w=1}^{W} P_{w_{-} e s t, b}^{t}=P_{\text {Load }, b}^{t}+P_{\text {loss }, b}^{t} \\
& P_{s w, c}^{t}+\sum_{s=1}^{S} P_{s_{-} e s t, c}^{t}+\sum_{w=1}^{W} P_{w_{-} e s t, c}^{t}=P_{\text {Load }, c}^{t}+P_{\text {loss }, c}^{t}
\end{aligned}
$$

$P_{\text {Load }, a}^{t} / P_{\text {Load }, ~}^{t} / P_{\text {Load }, c}^{t}:$ The load demand of the $\mathrm{a} / \mathrm{b} / \mathrm{c}$ phase at $t$-th time.

$P_{s w, a}^{t} / P_{s w, b}^{t} / P_{s w, c}^{t}$ : The power supply of the $\mathrm{a} / \mathrm{b} / \mathrm{c}$ phase at $t$-th time.

$P_{s_{-} e s t, a}^{t} / P_{s_{-} e s t, b}^{t} / P_{s_{-} e s t, c}^{t}$ : The VAR of PV output of the a/b/c phase at $t$-th time.

$P_{w_{-} e s t, a}^{t} / P_{w_{-} \_s t, b}^{\bar{t}} / P_{w_{-}}^{t} e s t, c$ : The VAR of WT output of the a/b/c phase at $t$-th time.

\subsection{Voltage Constraints}

The $i$-th bus voltage constraints at $t$-th time are described in Equation (10). Any scheme which violates the constraint does not select:

$$
V_{i,(a, b, c)}^{t} \geq V_{\min }
$$

$V_{i,(a, b, c)}^{t}$ : the $i$-th bus voltage magnitude of a/b/c phase at $t$-th time.

$V_{\text {min }}$ : lower limit of bus voltage magnitude.

\subsection{The Unbalance Factor Constraints}

The unbalance constraints at $t$-th time are described as in Equation (10).

$$
U F^{t} \leq U F_{\max }
$$

The unbalance factor of terminal bus at $t-t h$ time is calculated as in Equation (11).

$$
U F^{t}=\frac{\operatorname{Max}\left(\left|I_{s w, a}^{t}-I_{s w, a v g}^{t}\right|,\left|I_{s w, b}^{t}-I_{s w, a v g}^{t}\right|,\left|I_{s w, c}^{t}-I_{s w, a v g}^{t}\right|\right)}{I_{s w, a v g}^{t}} \times 100 \%
$$

$I_{s w, a g}^{t}$ : the average current of the three-phase of the terminal bus at $t$-th time. $I_{s w, a}^{t} / I_{s w, b}^{t} / I_{s w, c}^{t}:$ the current of the a/b/c phase of the terminal bus at $t$-th time. $U F_{\max }:$ upper limit of unbalance factor.

$U F^{t}$ : the unbalance factor of the terminal bus at $t$-th time. 
The fitness function is modified as:

$$
\mathrm{Fit}_{i}=\operatorname{Obj}\left(x_{i}\right)+\operatorname{pen}^{t}
$$

$O b j$ is the objective function and $p e n^{t}$ is the penalty value which is regulated in the searching process. The penalty value can be defined as:

$$
\begin{gathered}
\text { if } V_{i,(a, b, c)}^{t}<V_{\min } \text { then } V_{p e n}^{t}=\lambda_{v}\left|V_{\min }-V_{i,(a b c)}\right| \\
\text { if } U F^{t}>U F_{\max } \text { then } U F_{p e n}^{t}=\lambda_{U F}\left|U F_{\max }-U F^{t}\right| \\
\text { pen }{ }^{t}=V_{p e n}^{t}+U F_{p e n}^{t}
\end{gathered}
$$

If any variable violates their operated constraints, the penalty value will increase and the corresponding individual will be rejected to avoid producing an infeasible scheme.

\section{Solution Algorithm}

\subsection{Generation VAR of WTs/PVs}

VAR is a widely-used method for evaluating the uncertainty of power output of renewable sources under various scenarios [22,23]. Value-at-risk (VAR) is a method of measuring market risk. It is an evaluation of loss due to market fluctuations under a specific period and a specific probability. The desired maximal loss is defined in a given specific probability which is called the confidence level to represent the degree of VAR. Figure 2 is the diagram of VAR. Ninety-five percent is the common value of confidence level. This means that $95 \%$ of the time, the user's loss will be less than VAR, and $5 \%$ of the time, the user's loss will be greater than VAR. This paper proposes a VAR for representing the uncertainty of WTs/PVs under various scenarios. Based on the historical data available, the VAR of the WTs/PVs penetrated was calculated by using the Monte Carlo method.

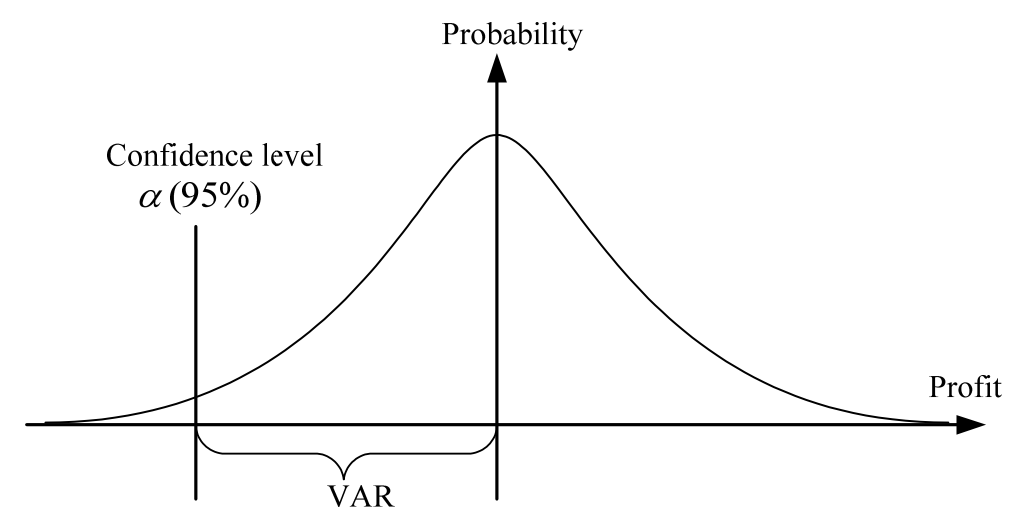

Figure 2. The diagram of VAR calculation.

Figure 3 shows the VAR of wind speed at the confidence levels of $95 \%$ and $90 \%$. The Monte Carlo method was used to simulate the VAR of wind speed 10,000 times. According to Figure 3, lower wind speed has a higher risk requirement and a relatively small WT power output. Similarly, Figure 4 shows the VAR of global radiation at the confidence levels of $95 \%$ and $90 \%$. To simulate the VAR of the confidence level of 95\% and 90\%, 10,000 samples were used. The Monte Carlo method was also used to simulate the VAR of global radiation 10,000 times and can get a better result [24]. 


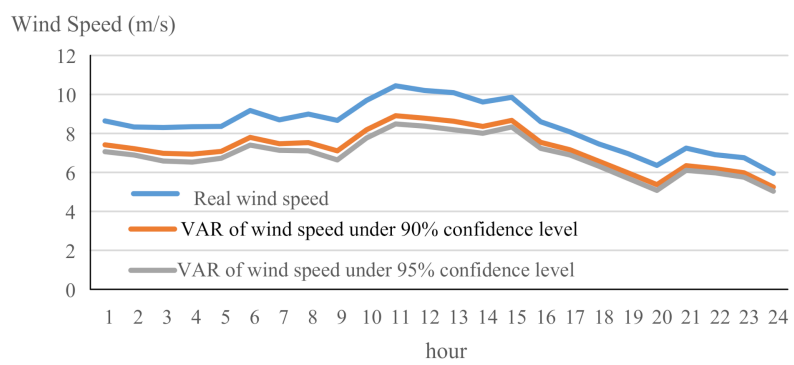

Figure 3. The VAR of wind speed at the confidence levels of $95 \%$ and $90 \%$.

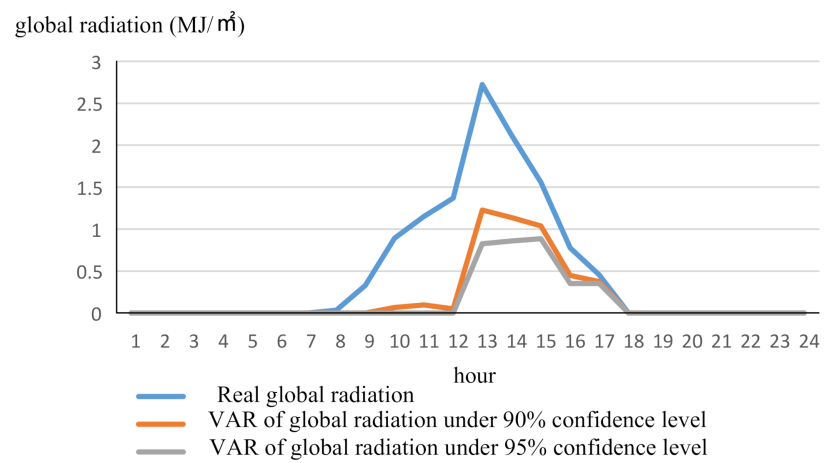

Figure 4. The VAR of global radiation at the confidence levels of $95 \%$ and $90 \%$.

By considering the VAR of wind speed and global radiation, the WT power output $\left(P_{w \_s s t}^{t}\right)$ can be expressed in Equation (17) and the PV power output $\left(P_{s_{-} e s t}^{t}\right)$ can be expressed in Equation (18).

$$
\begin{aligned}
P_{w_{-} \text {est }}^{t} & =\frac{1}{2} \rho C_{p}(\lambda, \theta) A\left(v_{t}^{\mathrm{var}}\right)^{3} \\
P_{s_{-} \text {est }}^{t} & =\eta_{P V} \times P_{G, \mathrm{var}}^{t} \times A_{P V}
\end{aligned}
$$

In this paper, the location of WTs/PVs is determined on the bus of the distribution feeder. Since the distribution feeder is located in a small area, the difference in energy productivity at different sites is not considered in this study.

\subsection{Feasible Particle Swarm Optimization (FPSO)}

Particle swarm optimization (PSO) was proposed in [25] for the problem of optimization in 1995. The search process of PSO imitates the mechanism of birds' (particles) flock flying. Each particle remembers its current optimal position (pbest), and the current global optimal position (gbest) in the population. Hence, PSO tries to reach compatibility between local search and global search. In the FPSO system, the position and velocity of particles is defined in Equation (19) and Equation (20) [26].

$$
\begin{gathered}
v_{i}^{t+1}=w \times v_{i}^{t}+c_{1} \times \operatorname{rand} \times\left(\text { pbest }_{i}^{t}-x_{i}^{t}\right)+c_{2} \times \text { rand } \times\left(\text { gbest }^{t}-x_{i}^{t}\right) \\
x_{i}^{t+1}=x_{i}^{t}+v_{i}^{t+1} \\
w^{t}=w_{\min }+\frac{\left(w_{\max }-w_{t}\right) \times\left(t_{\max }-t\right)}{t_{\max }}
\end{gathered}
$$

PSO has the characteristics of movement, evolution, elimination, and multiple variability. The movement in the PSO process is only dependent on the movement distance generated, and the movement information is transmitted between the particles. It is easy to converge to the local optimum. FPSO introduces the auto-adjust scheme by using the random parameter to assign the "infeasible solution $\left(\right.$ gbest $\left._{\text {inf }}\right)$ " and the "feasible solution $\left(\right.$ gbest $\left._{\mathrm{f}}\right)$ " into the solution space in order to make the 
PSO more efficient in the search for a global optimum as indicated in Figure 5. As indicated in Figure 5, the "infeasible solution $\left(g_{b e s t} t_{\text {inf }}\right)$ " space may be an attractive solution in the nearest future. An improvement on the auto-adjust scheme solution begins with finding the best direction to take in order to attain a global optimum. Hence, the velocity in FPSO can be modified as Equation (22).

$$
\begin{aligned}
& \text { if } \quad r<0.3 \\
& \text { then } \quad v_{i, j}^{t+1}=w \times v_{i, j}^{t}+c_{1} \times \text { rand } \times\left(\text { pbest }_{i, j}-x_{i, j}^{t}\right) \\
& \text { else if } \quad 0.3 \leq r \leq 0.7 \\
& \text { then } \quad v_{i, j}^{t+1}=w \times v_{i, j}^{t}+c_{1} \times \text { rand } \times\left(\text { pbest }_{i, j}-x_{i, j}^{t}\right) \\
& \text { else } \quad r>0.7 \\
& r>0.7 \quad+c_{2} \times \text { rand } \times\left(\text { gbest }_{j}-x_{i, j}^{t}\right) \\
& \text { then } \\
& \begin{aligned}
v_{i, j}^{t+1}= & w \times v_{i, j}^{t}+c_{1} \times \text { rand } \times\left(\text { pbest }_{i, j}-x_{i, j}^{t}\right) \\
& +c_{2} \times \text { rand } \times\left(\text { gbest }_{f, j}-x_{i, j}^{t}\right)
\end{aligned}
\end{aligned}
$$

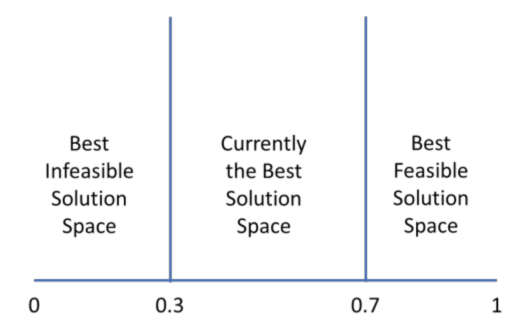

Figure 5. The auto-adjust scheme of FPSO.

\subsection{Implementation of Searching Procedure}

The implementation of the searching procedure is described as following steps.

(a) Calculate the transformer hourly loading in a TPC distribution feeder.

(b) Input the line data and bus data of the TPC distribution feeder. The bus data has the loads, types and phase of the distribution transformers, the number of WTs/PVs, and the generation VAR of the WTs/PVs.

(c) Randomly initialize 30 particles with feasible connection of distribution transformers, and the phase and location of WTs/PVs.

The phase rearrangement of distribution transformers and the location of WTs/PVs can be described as a binary state, so the initial solution is achieved by setting a binary value for the state of each particle. The initial feasibility state for each particle is defined by the Equations (23)-(28):

$$
x_{j, n}^{p^{\prime}}=\left[x_{j, n^{\prime}}^{p}, x_{\lambda, s^{\prime}}^{p} x_{\gamma s^{\prime}}^{p}, x_{\lambda, w^{\prime}}^{p} x_{\gamma, w}^{p}\right]
$$

$x_{j, n}^{p}=\left[x_{1, n^{\prime}}^{p} x_{2, n^{\prime}}^{p} \ldots, x_{j, n^{\prime}}^{p}, \ldots, x_{J-1, n^{\prime}}^{p} x_{J, n}^{p}\right]$ is the $n$-th connected state of distribution transformers corresponding to the $j$-th bus, which is defined as Equation (22).

$$
x_{j, n}^{p}=x_{j, \min }+\operatorname{round}\left[\text { rand } \times\left(x_{j, \max }-x_{j, \min }\right)\right]
$$

$x_{\lambda, s}^{p}=\left[x_{\lambda, 1^{1}}^{p}, x_{\lambda, 2^{2}}^{p}, \ldots, x_{\lambda, S}^{p}\right]$ is located at the $\lambda$-th bus of the $s$-th PV, as defined in Equation (23).

$$
x_{\lambda, s}^{p}=1+\operatorname{round}[\operatorname{rand} \times(N-1)]
$$


$x_{\gamma, s}^{p}=\left[x_{\gamma, 1}^{p} x_{\gamma, 2^{\prime}}^{p} \ldots, x_{\gamma, S}^{p}\right]$ is located at the $\gamma$-th phase of the s-th PV, as defined in Equation (24).

$$
x_{\gamma, S}^{p}=1+\operatorname{round}[\operatorname{rand} \times(3-1)]
$$

Similarly, $x_{\lambda, w}^{p}=\left[x_{\lambda, 1^{\prime}}^{p} x_{\lambda, 2^{\prime}}^{p} \ldots, x_{\lambda, W}^{p}\right]$ is located at the $\lambda$-th bus of the $w$-th WT and $x_{\gamma, w}^{p}=$ $\left[x_{\gamma, 1}^{p}, x_{\gamma, 2^{p}}^{p}, \ldots, x_{\gamma, W}^{p}\right]$ is located at the $\gamma$-th phase of the $s$-th WT.

$$
\begin{aligned}
x_{\lambda, w}^{p} & =1+\operatorname{round}[\operatorname{rand} \times(N-1)] \\
x_{j, w}^{p, \gamma} & =1+\operatorname{round}[\operatorname{rand} \times(3-1)]
\end{aligned}
$$

(d) Perform the load flow program with ECI and calculate the fitness values of each particle in the 24-hour interval. The fitness function is defined in Equation (13).

(e) Compare each particle's fitness value with the pbest. If the objective value is smaller than the pbest, set the value as the current pbest.

(f) If the penalty factor is equal to $0\left(p^{t} n^{t}=0\right)$, the best particle associated with the minimal pbest of all particles is set to the value of this pbest as the current $g_{b e s t}$.

(g) If the penalty factor is more than $0\left(\mathrm{pen}^{t}>0\right)$, the best particle is set to gbest inf.

(h) Perform the FPSO according to Equation (22) for each particle and update velocity and position vectors.

(i) The stopping condition is 100 generations. If the preset stopping condition is not yet reached, then go back to Step (d).

Figure 6 shows the flowchart of the searching procedure 


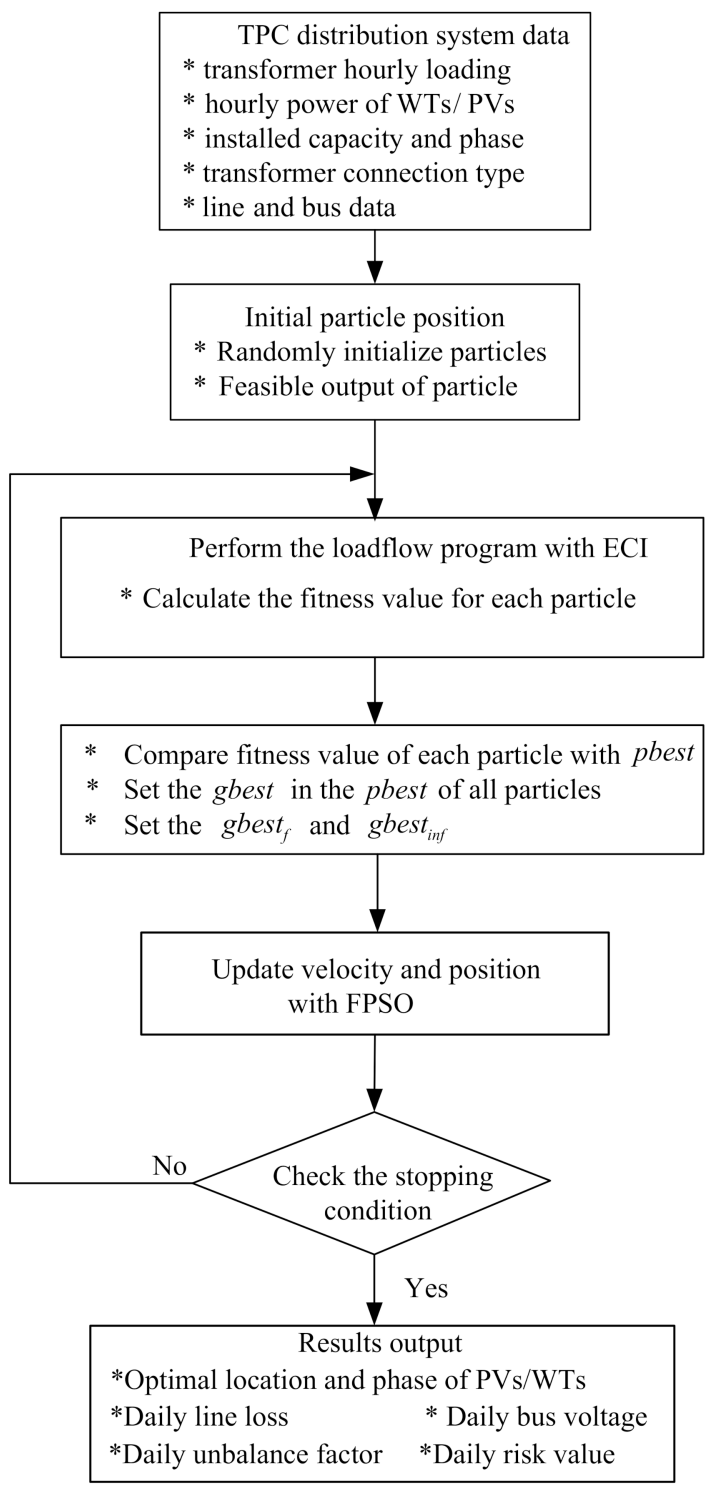

Figure 6. Flowchart of the searching procedure.

\section{Case Study}

To prove the effectiveness of the proposed algorithm, a Taipower feeder, as shown in Figure 7, was adopted to simulate its efficiency [27]. There are 32 buses in this feeder which serves residential, commercial, and several small-industrial customers. A total of 3648 different users are linked to the Taipower feeder. Table 2 shows the connected status of distribution transformers in this feeder. The rating output of WT and PV is $200 \mathrm{~kW}$ and $40 \mathrm{~kW}$, respectively. Two PVs and two WTs are installed on the bus of the distribution feeder. Three cases were simulated in this study.

Original Case: The original 32 buses configuration without WTs/PVs installed.

Case 1: The optimal phase connection of the transformers without considering the location of the WTs/PVs.

Case 2: The optimal phase connection of the transformers considering the location of the WTs/PVs. 
Table 2. The connected status of the distribution transformer.

\begin{tabular}{|c|c|c|c|c|c|c|c|c|c|c|c|}
\hline $\mathrm{Bus}_{i}$ & $T r$ & Load & $\mathrm{Bus}_{i}$ & $T r$ & Load & $\mathrm{Bus}_{i}$ & $T r$ & Load & $\mathrm{Bus}_{i}$ & $T r$ & Load \\
\hline 1 & - & - & 9 & $Y-\Delta$ & $\mathrm{A}, \mathrm{B}, \mathrm{C}$ & 17 & Open Y & $A, B$ & 25 & - & - \\
\hline 2 & - & - & 10 & $Y-\Delta$ & $\mathrm{A}, \mathrm{B}, \mathrm{C}$ & 18 & - & - & 26 & $1 \phi$ & A \\
\hline 3 & Open Y & A, B & 11 & $Y-\Delta$ & $\mathrm{A}, \mathrm{B}, \mathrm{C}$ & 19 & $Y-\Delta$ & $\mathrm{A}, \mathrm{B}, \mathrm{C}$ & 27 & $Y-\Delta$ & $A, B, C$ \\
\hline 4 & Open Y & $\mathrm{B}, \mathrm{C}$ & 12 & $Y-\Delta$ & $\mathrm{A}, \mathrm{B}, \mathrm{C}$ & 20 & Open Y & $\mathrm{A}, \mathrm{C}$ & 28 & Open $\mathrm{Y}$ & A, B \\
\hline 5 & - & - & 13 & Open Y & $\mathrm{A}, \mathrm{C}$ & 21 & - & - & 29 & $Y-\Delta$ & $A, B, C$ \\
\hline 6 & - & - & 14 & - & - & 22 & $1 \phi$ & B & 30 & Open Y & $\mathrm{A}, \mathrm{C}$ \\
\hline 7 & - & - & 15 & - & - & 23 & - & - & 31 & $Y-\Delta$ & $A, B, C$ \\
\hline 8 & Open Y & A, B & 16 & - & - & 24 & Open Y & $\mathrm{B}, \mathrm{C}$ & 32 & Open Y & $\mathrm{B}, \mathrm{C}$ \\
\hline
\end{tabular}

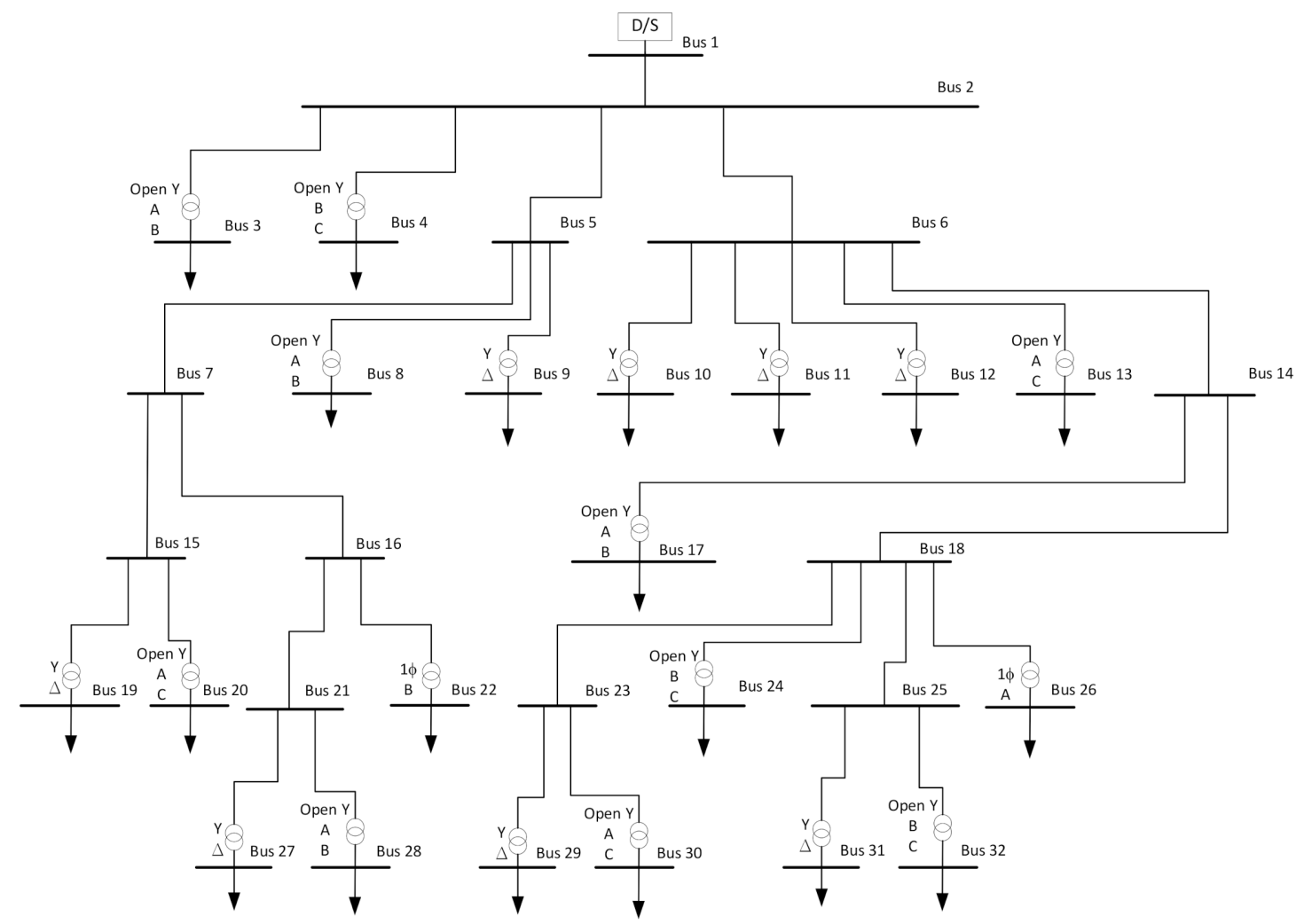

Figure 7. The practical feeder diagram.

\subsection{The Optimal Location of WTs and PVs}

Table 3 shows the optimal location of WTs and PVs in the different scenarios. WTs and PVs are installed at the bus location and phase location to minimize line loss. From Table 3, there are some differences in the optimal location of the bus and phase, with location at 90\% VAR and location at 95\% VAR, respectively.

Table 4 is the optimal phase connection of distribution transformers when the WTs/PVs are added to the distribution feeder in the various scenarios. The load phases of the transformer connections of bus $4,12,17,22,30$ do not need to be changed in all the scenarios and the other buses need to change the load phase of the transformer once, twice, or thrice in the various scenarios. 
Table 3. The optimal location of WTs and PVs in the different scenarios.

\begin{tabular}{lcccccc}
\hline & \multicolumn{2}{c}{ Optimal Location } & \multicolumn{2}{c}{ Location } & \multicolumn{2}{c}{ Location $\mathbf{9 5 \%}$ VAR } \\
& $\lambda$ & $\gamma$ & $\lambda$ & $\gamma$ & $\lambda$ & $\gamma$ \\
\hline WT1 & 19 & 1 & 19 & 1 & 18 & 3 \\
WT2 & 20 & 3 & 20 & 3 & 20 & 1 \\
PV1 & 17 & 3 & 17 & 3 & 18 & 1 \\
PV2 & 20 & 3 & 20 & 3 & 19 & 1 \\
\hline
\end{tabular}

$\lambda$ : bus location. $\gamma$ : phase location.

Table 4. The optimal phase connection of distribution transformers.

\begin{tabular}{|c|c|c|c|c|c|}
\hline Bus No. & $\begin{array}{c}\text { Transformer } \\
\text { Type }\end{array}$ & $\begin{array}{c}\text { Original } \\
\text { Connected }\end{array}$ & $\begin{array}{c}\text { Phase } \\
\text { Rearrangement }\end{array}$ & $\begin{array}{c}\text { Phase Rearrangement } \\
\text { with } \\
90 \% \text { VAR }\end{array}$ & $\begin{array}{c}\text { Phase Rearrangement } \\
\text { with } \\
95 \% \text { VAR }\end{array}$ \\
\hline 3 & $2 \phi$ & A, B & A, B & A, B & A to $C, B$ \\
\hline 4 & $2 \phi$ & $\mathrm{B}, \mathrm{C}$ & $\mathrm{B}, \mathrm{C}$ & $\mathrm{B}, \mathrm{C}$ & $\mathrm{B}, \mathrm{C}$ \\
\hline 8 & $2 \phi$ & A, B & A to $C, B$ & A to $C, B$ & A to $C, B$ \\
\hline 9 & $3 \phi$ & A, B, C & A to $C, B, C$ to $A$ & A to $C, B, C$ to $A$ & A to $C, B, C$ to $A$ \\
\hline 10 & $3 \phi$ & $\mathrm{A}, \mathrm{B}, \mathrm{C}$ & $\mathrm{A}, \mathrm{B}, \mathrm{C}$ & $\mathrm{A}, \mathrm{B}, \mathrm{C}$ & $\mathrm{A}, \mathrm{B}, \mathrm{C}$ \\
\hline 11 & $3 \phi$ & A, B, C & A to $C, B, C$ to $A$ & A to $C, B, C$ to $A$ & A to $C, B, C$ to $A$ \\
\hline 12 & $3 \phi$ & A, B, C & A, B, C & A, B, C & A, B, C \\
\hline 13 & $3 \phi$ & $\mathrm{A}, \mathrm{C}$ & A to $C, C$ to $A$ & A to $C, C$ to $A$ & A to $C, C$ to $A$ \\
\hline 17 & $3 \phi$ & A, B & A, B & A, B & A, B \\
\hline 19 & $3 \phi$ & A, B, C & A to $C, B, C$ to $A$ & A to $C, B, C$ to $A$ & A to $C, B, C$ to $A$ \\
\hline 20 & $3 \phi$ & $\mathrm{A}, \mathrm{C}$ & A to $C, C$ to $A$ & A to $C, C$ to $A$ & A to $C, C$ to $A$ \\
\hline 22 & $3 \phi$ & B & B & B & B \\
\hline 24 & $3 \phi$ & $\mathrm{B}, \mathrm{C}$ & $\mathrm{B}, \mathrm{C}$ to $\mathrm{A}$ & $\mathrm{B}, \mathrm{C}$ to $\mathrm{A}$ & $\mathrm{B}, \mathrm{C}$ to $\mathrm{A}$ \\
\hline 26 & $3 \phi$ & $\mathrm{A}$ & A to $C$ & A to $C$ & A to $C$ \\
\hline 27 & $3 \phi$ & A, B, C & A to $C, B$ to $A, C$ to $B$ & A to $C, B$ to $A, C$ to $B$ & A to $C, B, C$ to $A$ \\
\hline 28 & $3 \phi$ & A, B & A, B to $C$ & $\mathrm{~A}, \mathrm{~B}$ to $\mathrm{C}$ & A to $B, B$ to $C$ \\
\hline 29 & $3 \phi$ & A, B, C & A to $B, B$ to $C, C$ to $A$ & A to $B, B$ to $C$ & A, B, C \\
\hline 30 & $3 \phi$ & $\mathrm{A}, \mathrm{C}$ & $\mathrm{A}, \mathrm{C}$ & $\mathrm{A}, \mathrm{C}$ & $\mathrm{A}, \mathrm{C}$ \\
\hline 31 & $3 \phi$ & A, B, C & A to $C, B, C$ to $A$ & A to $C, B, C$ to $A$ & A to $C, B, C$ to $A$ \\
\hline 32 & $3 \phi$ & $\mathrm{B}, \mathrm{C}$ & $\mathrm{B}, \mathrm{C}$ & $\mathrm{B}, \mathrm{C}$ & $\mathrm{B}, \mathrm{C}$ to $\mathrm{A}$ \\
\hline
\end{tabular}

Note: $A$ to $C$ is changed from phase-A connection to phase- $C$ connection.

\subsection{The Optimal Phase Connection of the Transformers}

Figure 8 shows the comparisons for the daily minimal voltage profiles of all buses. In Figure 8 , the minimal voltage of all buses is operated from $0.938 \mathrm{pu}$ to $0.974 \mathrm{pu}$ in the original case, from $0.957 \mathrm{pu}$ to $0.983 \mathrm{pu}$ in Case 1, and from $0.956 \mathrm{pu}$ to $0.985 \mathrm{pu}$ in Case 2. In the original case, the minimal voltage is $0.937 \mathrm{pu}$, which violates operating limits. It can be shown that the voltage profiles can be improved after the phase arrangement and the installation of WTs/PVs.

Figure 9 shows the daily system unbalance factor at the terminal bus. In Figure 9, the maximal unbalance factor is $25 \%$ in the original case, $12 \%$ in Case 1, and $20 \%$ in Case 2. It is observed that the proper phase arrangement will get a lower unbalance factor than that without phase re-arrangement.

Figure 10 shows the daily system loss profiles. The daily system loss is improved after phase rearrangement and installation of WTs/PVs. Total system loss is $945.775 \mathrm{~kW}$ in the original case, $901.860 \mathrm{~kW}$ in Case 1, and $679.459 \mathrm{~kW}$ in Case 2. As Figure 10 indicates, the profiles with WTs/PVs installed and phase rearrangement have more loss reduction. 


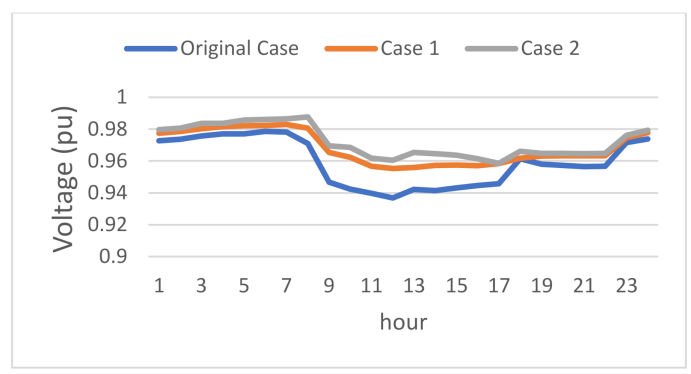

Figure 8. The daily minimal voltage profiles of all buses.

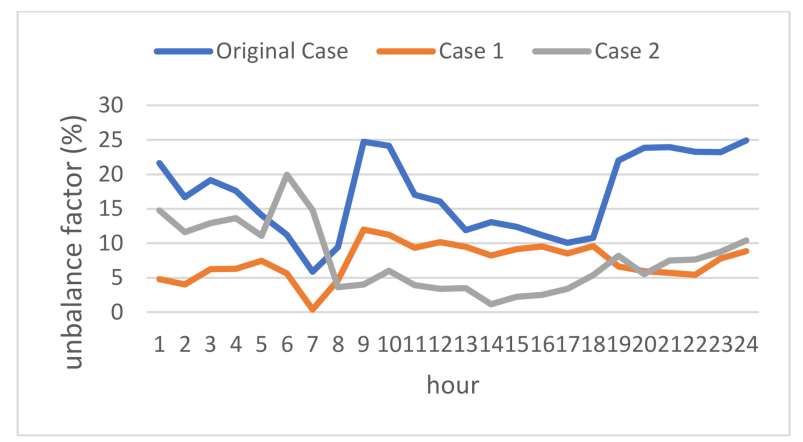

Figure 9. The daily system unbalance factor at the terminal bus.

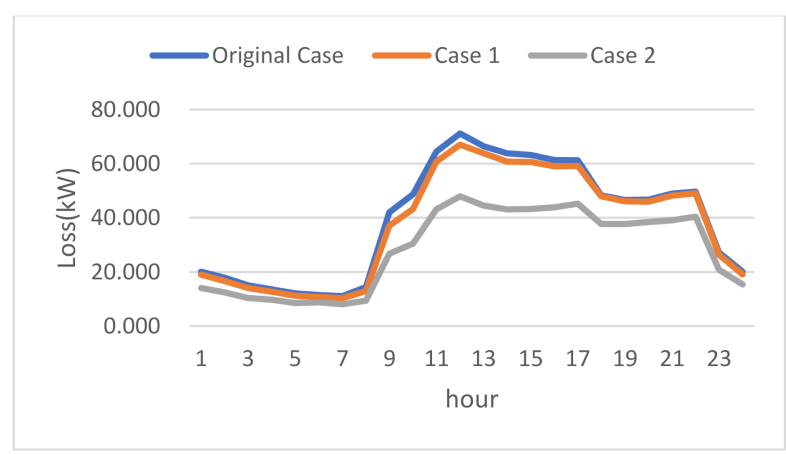

Figure 10. The daily system loss profiles.

\subsection{The Optimal Phase Connection of the Transformers Considering the Generation of WTs/PVs}

Figure 11 shows the VAR of daily minimal voltage at the various confidence levels $(\alpha=100 \%$, $\alpha=95 \%, \alpha=90 \%$ ). The VAR of minimal voltage in a day corresponding to $100 \%, 95 \%$, and $90 \%$ is $0.958 \mathrm{pu}, 0.962 \mathrm{pu}$, and $0.961 \mathrm{pu}$, respectively. According to Figure 11, a higher VAR of minimal voltage results in a higher confidence level, which also leads to lower risk.

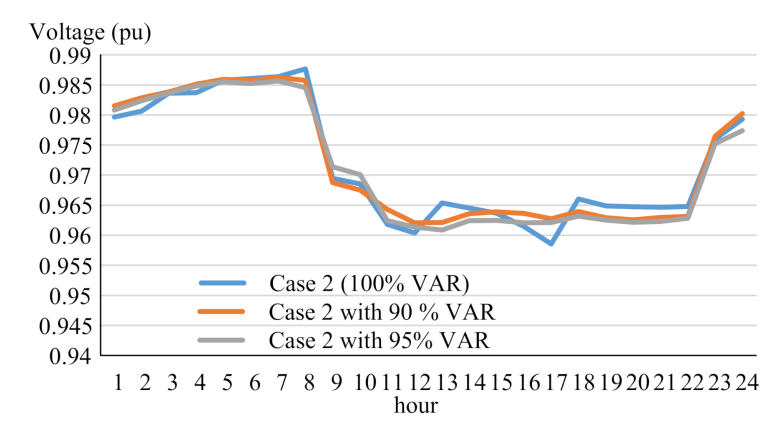

Figure 11. The VAR of daily minimal voltage in the various confidence levels. 
Figure 12 shows the VAR of the daily unbalance factor at the various confidence levels $(\alpha=100 \%$, $\alpha=95 \%, \alpha=90 \%$ ). The VAR of the maximal unbalance factor in a day corresponding to $100 \%, 95 \%$, and $90 \%$ is $19.9348 \%, 14.803 \%$, and $10.683 \%$, respectively. As seen in Figure 12, a higher confidence level leads to a lower VAR of maximal unbalance factor, which means lower risk.

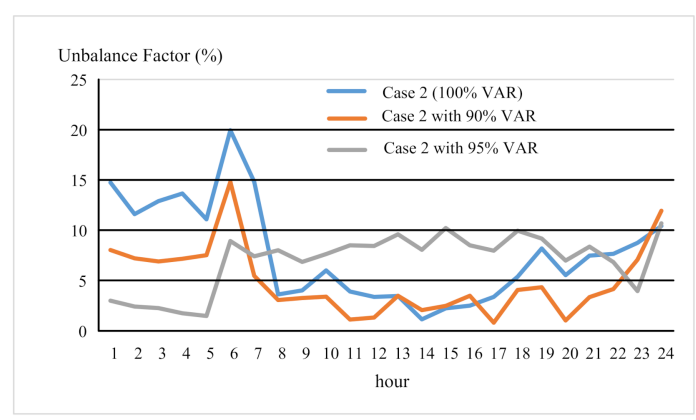

Figure 12. The VAR of daily unbalance factor at the various confidence levels.

Figure 13 shows the VAR of daily system loss at the various confidence levels $(\alpha=100 \%, \alpha=95 \%$, $\alpha=90 \%$ ). The VAR of total loss in a day corresponding to $100 \%, 95 \%$, and $90 \%$ is $679.459 \mathrm{~kW}, 701.624 \mathrm{~kW}$, and $703.766 \mathrm{~kW}$, respectively. Similarly, a higher confidence level leads to a higher VAR of system loss, which is lower risk.

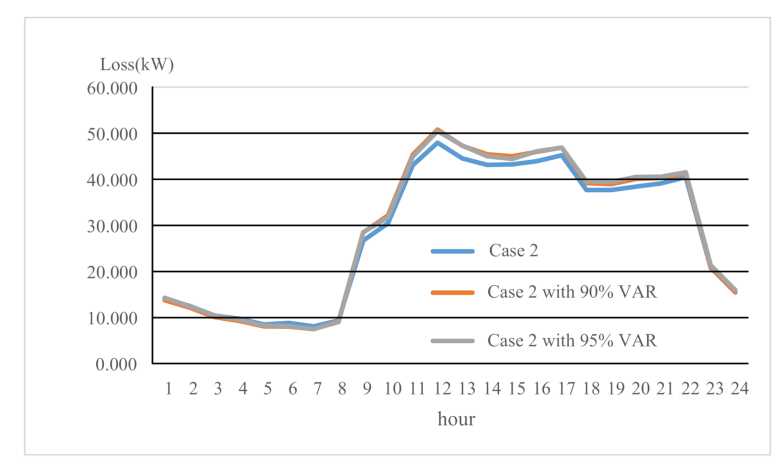

Figure 13. The VAR of daily system loss at the various confidence levels.

\subsection{Convergence Test}

Figure 14 illustrates the convergence characteristics of PSO, time variable acceleration coefficient with PSO (TVAC-PSO) [28], PSO with constriction factor (PSO-CF) [29], and FPSO in Case 2. The tests were carried out on an Intel core i7-6700 3.4GHz CPU with 8 GB DRAM memory. In Figure 14, the improvement of the FPSO over other algorithms is clear. Table 5 shows the maximum, minimum, and average convergent fitness values tested in Case 2 at 100 times. Although the solution's improvement is subtle, it shows the ability of the FPSO to look for a global optimal position.

Table 5. The comparison of PSO, TVAC-PSO, PSO-CF, and FPSO in Case 2.

\begin{tabular}{ccccc}
\hline & PSO & TVAC-PSO & PSO-CF & FPSO \\
\hline Max. Convergent Fitness Value & 959.098 & 927.018 & 897.813 & 861.843 \\
\hline Min. Convergent Fitness Value & 758.617 & 697.927 & 693.345 & 679.459 \\
\hline Average Convergent Fitness Value & 826.085 & 781.681 & 768.916 & 744.558 \\
\hline CPU Time (sec) & 48.67 & 56.184 & 83.731 & 60.821 \\
\hline
\end{tabular}

TVAC-PSO: time variable acceleration coefficient with PSO [28]. PSO-CF: PSO with constriction factor [29]. 


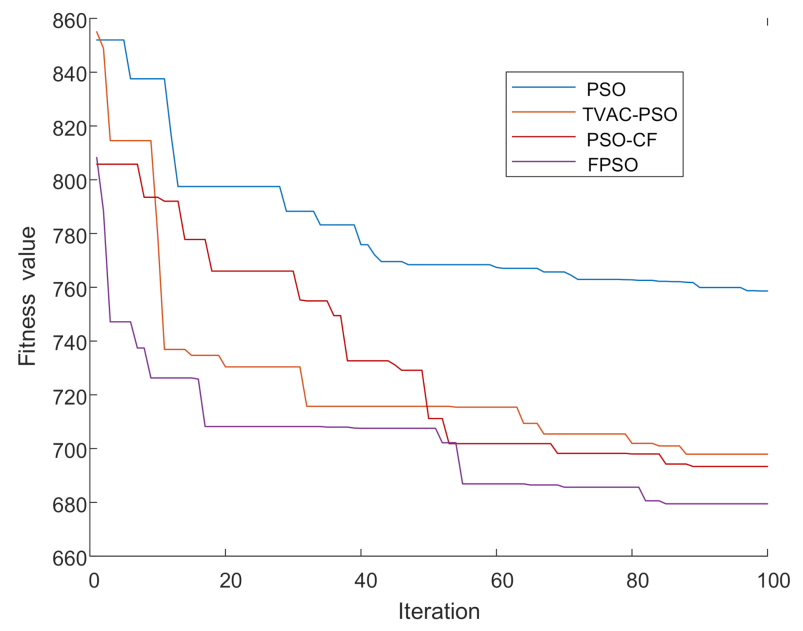

Figure 14. The convergence characteristics of PSO, time variable acceleration coefficient with PSO (TVAC-PSO), PSO with constriction factor (PSO-CF), and FPSO in Case 2.

\section{Conclusions}

This paper presents a FPSO to find the optimal phase arrangement of distribution transformers, which minimizes the system losses for improving the system unbalance and voltage profile. By considering the WTs/PVs installed, the optimal location and VAR of power generation are simultaneously integrated into the searching procedure. The FPSO is proposed to determine the optimal location of WTs/PVs and the arrangement of distribution transformers in contexts of uncertainty. According to the optimal WT/PV location and phase assignment of distribution transformers, the system loss, minimal voltage profiles, and unbalance factor are solved by the ECI three-phase load flow analysis. The effectiveness of the FPSO in solving the phase arrangement procedure was tested on a 32-bus Taipower distribution feeder; it can explore the impact of uncertainty and risk aversion on phase arrangement of distribution transformers decisions with high renewable penetration. Results can help operators to process more valuable information for improving system unbalance, voltage profiles, and system loss. The proposed algorithm can also be applied in the power system planning and operation of many mixed integer optimization problems in the future.

WTs/PVs are a key development for the purpose of global sustainability trends in renewable energy. Influenced by factors of geography, circumstance, and climates, WTs/PVs are intermittent, volatile, and uncontrollable. Based on the historical wind speed/global radiation and corresponding power output data, a VAR model of WT/PV is simply presented in this study. Due to the energy potential of WT/PV being dependent upon the location of the local area, the influencing factors were retrieved from the Central Weather Bureau Observation Data Inquire System [30] to forecast the power output of WT/PV. It not only improves the forecast model availability, but also enhances the forecasting accuracy in our further research.

Author Contributions: C.-S.T. is the first author. He provided hardware tools, the system model, and related materials experimental model results. C.-Y.Y. performed the experiments and conducted simulations. M.-T.T. generalized the FPSO model and designed system planning projects. All the authors were involved in exploring system validation and results, and permitting the benefits of the published document. All authors have read and agreed to the published version of the manuscript.

Funding: This research received no external funding.

Acknowledgments: The authors would like to acknowledge the financial support from the Ministry of Science and Technology of Taiwan, R.O.C. for this study through the grant: MOST 107-2221-E-230 -008-MY3.

Conflicts of Interest: The authors declare no conflict of interest. 


\section{Abbreviations}

$\begin{array}{ll}\text { Symbols } & \text { Abbreviations } \\ \rho & \text { air density }\left(\mathrm{kg} / \mathrm{m}^{3}\right) \\ A & \text { the rotor area }\left(\mathrm{m}^{2}\right) \\ v_{t} & \text { the speed of WT }(\mathrm{m} / \mathrm{s}) \text { at } t \text {-th time } \\ v_{t}^{\mathrm{var}} & \text { the VAR of wind speed }(\mathrm{m} / \mathrm{s}) \text { at } t \text {-th time } \\ \lambda & \text { the ratio of tip speed } \\ \theta & \text { the pitch angle of rotor blades }(\mathrm{deg} .) \\ P_{G}^{t} & \text { the global radiation }\left(w / \mathrm{m}^{2}\right) \text { at } t \text {-th time } \\ A_{P V} & \text { the PV array area }\left(\mathrm{m}^{2}\right) \\ \eta_{P V} & \text { the operating efficiency of PV } \\ P_{G, \text { var }}^{t} & \text { the VAR of global radiation }\left(w / \mathrm{m}^{2}\right) \text { at } t \text {-th time } \\ c_{1} / c_{2} & \text { acceleration constant } \\ r a n d & \text { uniformly distributed random variables between } 0 \text { and } 1 \\ x_{i}^{t} & \text { the position of particle } i \text { at iteration } t \\ v_{i}^{t} & \text { the velocity of particle } i \text { at iteration } t \\ p b e s t_{i}^{t} & \text { the own best position of particle } i \text { at iteration } t \\ g b e s t^{t} & \text { the best particle in the swarm at iteration } t \\ w^{t} & \text { the inertia weight at iteration } t . w_{\text {max }}=2 \text { and } w_{\text {min }}=0.1\end{array}$

\section{References}

1. Chang, C.Y.; Yu, J.S.; Chen, C.S. Effects of open-wye/open-delta transformers on the operation of distribution systems. Electr. Power Syst. Res. 1986, 10, 1671-1674. [CrossRef]

2. Huang, S.J.; Tai, T.Y.; Liu, X.Z.; Su, W.F.; Gu, P.H. Application of bird-mating optimization to phase adjustment of open-wye/open-delta transformers in a power grid. In Proceedings of the IEEE International Conference on Industrial Technology (ICIT), Seville, Spain, 17-19 March 2015; Volume 1, pp. 12279-12751.

3. Chin, H.C.; Chung, R.J.; Yu, J.S.; Sun, H.H. Application of the ant colony system for open wye-open delta transformer's phase sequence adjustment. In Proceedings of the IEEE Region 10 TENCON 2004 Conference, Chiang Mai, Thailand, 21-24 November 2004; pp. 432-435.

4. Adefarati, T.; Bansal, R.C. Integration of renewable distributed generators into the distribution system: A review. IET Renew. Power Gener. 2016, 10, 8738-8784. [CrossRef]

5. Mahmud, K.; Khan, B.; Ravishankar, J.; Ahmadi, A.; Siano, P. An internet of energy framework with distributed energy resources, prosumers and small-scale virtual power plants: An overview. Renew. Sustain. Energy Rev. 2020, 127, 109840. [CrossRef]

6. Yuen, R.; Stoev, S.; Cooley, D. Distributionally robust inference for extreme Value-at-Risk. Insur. Math. Econ. 2020, 92, 708-709. [CrossRef]

7. Pérez, O.R.; Watts, D.; Flores, Y. Planning in a changing environment: Applications of portfolio optimisation to deal with risk in the electricity sector. Renew. Sustain. Energy Rev. 2018, 82, 38083-38823. [CrossRef]

8. Chen, T.H.; Cherng, J.T. Optimal phase arrangement of distribution transformers connected to a primary feeder for system unbalance improvement and loss reduction using a Genetic algorithm. IEEE Trans. Power Syst. 2000, 15, 9941.

9. Su, Y.S.; Lin, W.M.; Chang, S.C.; Tsay, M.T. Application of the normalized weighting method for the connections between distribution transformers and a primary feeder. In Proceedings of the 2004 IEEE Region 10 Conference TENCON, Chiang Mai, Thailand, 24-24 November 2004; pp. 4451-4484.

10. Abril, I.P. NSGA-II phase balancing of primary distribution circuits by the reconnection of their circuit laterals and distribution transformers. Electr. Power Syst. Res. 2014, 109, 1-7. [CrossRef]

11. Abril, I.P. Genetic algorithm for the load balance on primary distribution circuit. IEEE Lat. Trans. 2010, 8, 5231-5265. [CrossRef]

12. Singh, D.; Misra, R.K.; Mishra, S. Distribution system feeder re-phasing considering voltage-dependency of loads. Int. J. Electr. Power Energy Syst. 2016, 76, 1071-1109. [CrossRef] 
13. Ali, B.; Siddique, I. Distribution system loss reduction by automatic transformer load balancing. In Proceedings of the International Multi-topic Conference (INMIC), Lahore, Pakistan, 24-26 November 2017; Volume 1, pp. 1-5.

14. Kuo, C.C. Application of the normalized weighting method for the connections between distribution transformers and a primary feeder. In Proceedings of the 39th International Universities Power Engineering Conference, Bristol, UK, 6-8 September 2004; Volume 1, pp. 343-348.

15. Tsay, M.T.; Chan, S.Y. The optimal loss reduction of distribution feeder based on transformer rearrangement. Int. J. Electr. Power Energy Syst. 2001, 23, 3433-3448. [CrossRef]

16. Tsay, M.T.; Chan, S.Y. Improvement in system unbalance and loss reduction of distribution feeders using transformer phase rearrangement and load diversity. Int. J. Electr. Energy Energy Syst. 2003, 25, 3901-3954. [CrossRef]

17. Maria, T.C.C.; Daniel, D.A.; Elisa, T.B. Locational impact and network costs of energy transition: Introducing geographical price signals for new renewable capacity. Energy Policy 2020, 141, 111469. [CrossRef]

18. Chang, C.T. Multi-choice goal programming model for the optimal location of renewable energy facilities Renewable and Sustainable. Energy Rev. 2015, 41, 3789-3793.

19. Reyes, A.; Sucar, L.E.; Lbargüengoytia, P.H.; Morales, E.F. Planning under uncertainty applications in power plants using factored markov decision processes. Energies 2020, 13, 2302. [CrossRef]

20. Acebrón, J.A.; Herrero, J.R.; Monteiro, J. A highly parallel algorithm for computing the action of a matrix exponential on a vector based on a multilevel Monte Carlo method. Comput. Math. Appl. 2020, 79, 34515-34953. [CrossRef]

21. Lin, W.M.; Teng, J.H. Three-phase distribution network fast-decoupled power flow solutions. Int. J. Electr. Power Energy Syst. 2000, 22, 3753-3780. [CrossRef]

22. Alexander, C. Risk Management and Analysis_Volume 1 Measuring and Modelling Financial Risk; John Wiley \& Sons Ltd.: Hoboken, NJ, USA, 2000.

23. Marrison, C. Fundamentals of Risk Measurement; McGraw-Hill Companies, Inc.: New York, NY, USA, 2002.

24. Mastsumoto, M.; Ohori, R.; Yoshiki, T. Approximation of Quasi-Monte Carlo worst case error in weighted spaces of infinitely times smooth functions. J. Comput. Appl. Math. 2018, 33, 1551-1564.

25. Kennedy, J.; Eberhart, R.C. Particle Swarm Optimization. In Proceedings of the IEEE International Conference on Neural Networks, Perth, Australia, 27 November-1 December 1995; Volume 4, pp. 19421-19948.

26. Chaturvedi, K.T.; Pandit, M.; Srivastava, I. Self-organizing hierarchical particle swarm optimization for nonvex economic dispatch. IEEE Trans. Power Syst. 2008, 23, 10798-107987. [CrossRef]

27. Chang, S.C. Transformer Load Connection and Loss Reduction for Distribution Feeder Circuits. Master's Thesis, National Sun Yat-Sen University, Kaohsiung City, Taiwan, 1997.

28. Rituraj, S.P.; Nitin, N.; Harish, G. A novel TVAC-PSO based mutation strategies algorithm for generation scheduling pumped storage hydrothermal system incorporating solar units. Energy 2018, 142, 8228-8237.

29. Shi, Y.; Eberhart, R.C. A Modified Particle Swarm Optimizer. In Proceedings of the IEEE International Conference on Evolutionary Computation, Anchorage, AK, USA, 4-9 May 1998; pp. 693-697.

30. Central Weather Bureau Observation Taiwan. 2020. Available online: https://www.cwb.gov.tw/V7/observe/ (accessed on 1 March 2020).

Publisher's Note: MDPI stays neutral with regard to jurisdictional claims in published maps and institutional affiliations.

(C) 2020 by the authors. Licensee MDPI, Basel, Switzerland. This article is an open access article distributed under the terms and conditions of the Creative Commons Attribution (CC BY) license (http://creativecommons.org/licenses/by/4.0/). 